\title{
Identidades étnicas e Etnociências nas práticas de Rezadeiras
}

\author{
Graciela Souza Almeida' \\ Programa de Pós-Graduação em Relações Étnicas e Contemporaneidade \\ Natalino Perovano Filho' \\ Programa de Pós-Graduação em Relações Étnicas e Contemporaneidade
}

\author{
Dossiê | Dossier | Dosier \\ DOI do artigo: 10.22481/odeere.v6i2.9750
}

\begin{abstract}
RESUMO
O presente estudo acerca das atividades praticadas por rezadeiras no Brasil teve o intuito de identificar as identidades étnicas e as etnociências que compõem a pluralidade dos grupos sociais nos quais elas atuam e qual a sua importância para os meios. O objetivo, portanto, foi identificar as diferentes identidades étnicas que influenciam as práticas das rezadeiras. Para isso, foi adotada a metodologia da pesquisa bibliográfica de cunho exploratório descritivo e qualitativa a fim de obter uma visão sistemática do assunto. O estudo se justifica devido a importância em conhecer as identidades éticas bem como a etnociência existente nas práticas das rezadeiras, resgatando conhecimentos históricos e uma riqueza cultural fundamental para boa parte da população brasileira uma vez que estudos na área são escassos. Foram analisados 15 artigos que pautam sobre as práticas das rezadeiras, e os resultados obtidos apontaram que há muitas semelhanças entre as práticas de rezadeiras em diferentes regiões do Brasil e suas diferenças estão relacionadas, provavelmente, às origens que esses povos possuem. Portanto, conclui-se que vieram de matrizes africanas e indígenas principalmente e que possuem ainda mais semelhanças devido ao intercâmbio realizado entre algumas dessas culturas no território brasileiro.
\end{abstract}

Palavras-chave: Ełnociências. Rezadeiras. Identidades étnicas.

\section{Ethnic identities and Ethnosciences in the practices of Healers} ABSTRACT

The present study about the activities practiced by faith healers in Brazil aimed to identify the ethnic identities and ethnosciences that make up the plurality of social groups in which they work and what is their importance for the media. The objective, therefore, was to identify the different ethnic identities that influence the practices of the healers. For this, the bibliographic research methodology of descriptive and qualitative exploratory nature was adopted in order to obtain a systematic view of the subject. The study is justified due to the importance of knowing the ethical identities as well as the ethnoscience existing in the practices of the healers, recovering historical knowledge and a fundamental cultural wealth for a good part of the Brazilian population, since studies in the area are scarce. Fifteen articles on the practices of rezadeiras were analyzed, and the results obtained showed that there are many similarities between the practices of rezadeiras in different regions of Brazil and their differences are probably related to the origins that these peoples have. Therefore, it is concluded that they came from mainly African and indigenous matrices and that they have even more similarities due to the exchange between some of these cultures in the Brazilian territory.

Keywords: Ethnoscience. Healers. Ethnic Identities.

Submetido em: 26/10/2021 | Aceito em: 24/11/2021

1 Graduada em História (2012) e Pedagogia (2020). Especialista em Metodologia do Ensino Superior (2013) Especialista em Antropologia com Enfase Culturas Afro-Brasileiras (2014) pela UESB, campus de Jequié e Especialista em Coordenação Pedagógica (2019) Mestranda em Relações Étnicas e Contemporaneidade (PPGREC-UESB).E-mail: gracybarbosa@gmail.com

2 Doutorado em 2016 (UESC), Docente permanente do Programa de Pós-Graduação em Relações Étnicas e Contemporaneidade. E-mail: npfilho@uesb.edu.br 


\section{INTRODUÇÃO}

As Rezadeiras praticam a reza como principal atividade. Podem ser chamadas também de curandeiras e benzedeiras. Contudo, existem diferenças para designar a função de rezadeiras, benzedeiras e curandeiros. De acordo com Santos, (2009), os curadores, diferentemente das benzedeiras, possuem a capacidade de se conectar com forças superiores além da oração e da bênção, e em sua maioria são homens. As rezadeiras através das rezas e preces desempenham um importante papel nas comunidades em que estão inseridos, não obstante a isso, essas mulheres guardam um grande conhecimento passado de gerações para gerações.

Entretanto, múltiplas culturas existem no Brasil e, por conseguinte, muitas identidades étnicas compõem as peculiaridades de cada cultura e por conseguinte, há uma grande riqueza a ser explorada pela etnociência nas práticas das rezadeiras. Dessa forma, o presente artigo objetiva identificar as diferentes identidades étnicas que influenciam as práticas das rezadeiras. O estudo parte da questão norteadora: quais as raízes dos conhecimentos etnocientíficos existentes para o desenvolvimento das práticas das rezadeiras?

O estudo se justifica devido a importância em conhecer as identidades éticas bem como a etnociência existente nas práticas das rezadeiras, resgatando conhecimentos históricos e uma riqueza cultural fundamental para boa parte da população brasileira. Além disso, dissertar acerca do papel dessas figuras na sociedade é algo substancial, uma vez que rezadeiras, benzedeiras e curandeiros exercem suas atividades como cuidadores da saúde e do bem estar físico das pessoas, ligados à espiritualidade e à fé.

O problema da pesquisa está vinculado à escassez da produção de pesquisas científicas e materiais bibliográficos com o intuito de resgatar aspectos das culturas, sociais, religiosos e também sobre as origens das tradições acerca das práticas realizadas por rezadeiras. Dessa forma, o presente estudo visa apresentar a partir de uma visão sistematizada o tema proposto, trazendo informações relevantes para descrever os fenômenos.

Para tanto, a metodologia escolhida foi de pesquisa bibliográfica de caráter exploratório e descritivo, a partir de uma abordagem qualitativa. Dessa forma, deverão ser pesquisados artigos, monografias, teses, livros, e outros trabalhos e 
publicações científicas e acadêmicas disponíveis em plataformas como a Scielo, e também em bases de dados acadêmicas de instituições de ensino superior. Por conseguinte, deverão ser identificados, descritos, organizados, analisados os dados obtidos gerando o referencial teórico, resultados e discussões e por fim a conclusão do trabalho.

\section{ETNOCIÊNCIAS}

O campo de estudos no Brasil das religiões populares também investiga a medicina religiosa, a partir da etnociência, que é o estudo das outras realidades, do conhecimento das relações e interações, do uso e manejo dos recursos naturais pelas comunidades locais através do tempo, de todos os processos culturais envolvidos nas relações povos-natureza (EMBRAPA, 2007). Assim, a etnociência

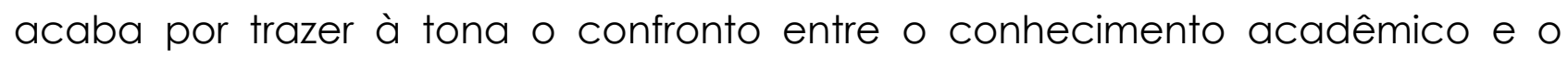
conhecimento popular.

Desde o seu surgimento, o uso do termo "populações tradicionais" tem sido bastante questionado no meio acadêmico. Entretanto, o termo é utilizado nesse contexto em sentido amplo para os propósitos deste texto. As "populações tradicionais" são aquelas que possuem conhecimento da natureza, que se relacionam de forma muito íntima, em simbiose e dependência, conhecendo os segredos, suas propriedades e utilizando dos seus recursos para viver e transmitindo esses valores de geração a geração (STEFANELLO, 2012).

Dessa forma, devem-se estudar conhecimentos e conceitos desenvolvidos por culturas sobre determinada área, no caso do presente estudo, a "medicina religiosa". Esses conhecimentos costumam ser específicos de povos e etnias pertencentes a uma determinada cultura. Diferentes povos foram se adaptando e desenvolvendo os seus próprios meios de lidar com a natureza, como organizar o espaço ou utilizar os recursos naturais, muitas vezes permeados por crenças, superstições ou pela fé religiosa, esses conhecimentos sobre a natureza e a relação do ser humano com ela acabaram por ser acumulados e passados de geração para geração (DINIZ, Ericka; DINIZ, Emerson. 2019).

A etnociência tem como característica fundamental a interdisciplinaridade das ações e, nos últimos anos, tem buscado o reconhecimento do valor intelectual do etnoconhecimento e formas de retorno àqueles que o geram (EMBRAPA, 2007). O reconhecimento desses conhecimentos culturais é substancial para que sejam 
respeitadas as diferentes culturas que existem no Brasil e para que esses povos possam expressar sua cultura sem ter a necessidade de permanecer em forma de resistências perante a imposição de outra cultura. Um exemplo é a notícia publicada em 23 de agosto de 2021 pelo Le Monde Diplomatique Brasil, em que um local de reza e cura, a casa de medicina tradicional da Kunhã Yvoty dona Lúcia, na aldeia Amambai, no Mato Grosso do Sul, fundada por mulheres Guarani e Kaiowá, sofreu ameaças e insultos por pessoas da religião evangélica. No local são realizados rituais de cura e partos. São situações como essas que preocupam a liberdade de expressão das diferentes culturas existentes no Brasil e que desempenham papel fundamental para as comunidades, como as rezadeiras, parteiras, entre outros.

Sabe-se que a falta de estudos bem como a falta de respeito para com essas religiões, a intolerância religiosa, entre outros, são também um dos motivos para que as pesquisas voltadas ao conhecimento etnocientífico sobre as práticas das rezadeiras não sejam realizadas. Além disso, as atividades e centros de atendimento à comunidade sofrem ameaças e muitos já foram impedidos de dar continuidade às suas atividades. Da mesma forma, os conhecimentos não científicos, mas que são passados oralmente de geração para geração correm o risco de cair no esquecimento (BASTOS, 2013).

A etnociência, através da etnografia, registra os saberes tradicionais e locais, "por meio da qual as culturas deixam de ser vistas como conjuntos de artefatos e comportamentos e passam a ser considerados sistemas de conhecimentos ou de aptidões mentais, como revelados pelas estruturas linguísticas" (SILVA; FRAXE, 2013).

\subsection{IDENTIDADES ÉTNICAS}

De acordo com POUTIGNAT e STREIFF-FENART (1998) a etnicidade em si é uma forma de organização social, baseada na atribuição categorial que classifica as pessoas em função de sua origem suposta. Os signos culturais podem ser os aspectos diferenciadores dessas pessoas, que são agrupadas de acordo com os traços culturais que possuem uma origem comum.

A fim de compreender a diversidade que existe no Brasil, é importante fazer menção à sua história, ou seja, a origem das etnicidade existentes. De acordo com Silva (2017) "as culturas populares de cura praticadas no Brasil foram constituídas por uma "mistura étnica e religiosa dos povos que aqui se encontravam com os 
que chegaram". Primeiramente, o conhecimento acerca da cura a partir do uso de ervas e rituais advindos dos indígenas foram, muitos deles, praticamente extintos pela imposição da cultura ocidental europeia após a colonização do Brasil pelos portugueses. Dessa forma, muito da cultura indígena se perdeu ou algumas foram extintas. Além disso, as crenças e também conhecimentos sobre uso de ervas para cura, trazidas de diferentes tribos africanas pelos afrodescendentes brutalmente escravizados pelos europeus deixou um legado com uma grande variedade cultural. Isso pode ser visto nos dias atuais, de acordo com Oliveira e colaboradores (2019):

\begin{abstract}
O sincretismo religioso e a interação entre diferentes culturas abriram as portas de uma religiosidade múltipla, reagrupada de acordo com (SANCHI 2001) em subcampos que se aproximam ou se distanciam, configurando-se para a realidade brasileira como expressões do cristianismo católico e do universo das religiões de matrizes africanas. Contudo, (BRANDÃO 1986) vai dizer que estes habitus populares sofrem influências do trabalho cultural e religioso de grupos eclesiais, agentes ibéricos, afro-brasileiros e mais recentemente de espíritas kardecistas.
\end{abstract}

No entanto, atualmente há em todas as regiões do Brasil religiões com influências de matrizes africanas ou indígenas. Ambas possuem culturalmente pessoas capazes de dar bênçãos ou promover cura, através de rezas ou rituais, simpatias, bem como atendem à comunidade para diversos fins, cada qual com as características próprias de sua origem.

\begin{abstract}
Essa mescla da cultura negra e indígena na benzedura é sentida na presença de elementos de origem indígena, como os chás utilizados como remédios naturais e banhos utilizados nos processos de cura. E a mistura da cultura negra e europeia é sentida na presença de elementos do catolicismo popular (SILVA, 2017)
\end{abstract}

Assim, podemos ver que alguns estudos falam sobre esses grupos de rezadeiras em diversos locais do Brasil.

De acordo com a região, as práticas podem ser distintas, no entanto, suas similaridades estão atreladas às suas origens. De acordo com SILVA (2017), as rezadeiras na comunidade quilombola, em Contas, Bahia, materializam a cura através dos conhecimentos passados por muitos anos entre as gerações, e assim, desempenham um papel fundamental nas comunidades. O relato da própria autora menciona que as crianças da geração passada agora levam os seus filhos para serem benzidos, conforme era feito durante a infância delas. Outro estudo 
sobre as comunidades quilombolas propostos por MENDES e CAVAS (2018) apontam também as benzedeiras e os benzedeiros como cuidadores dos males físicos e espirituais dos moradores das comunidades quilombolas.

Para a autora, SILVA (2017) "curar é uma das atividades mais significativas da complexidade humana, pois representa a capacidade de superar uma adversidade (doença ou mal), uma desordem que aflige o corpo e a mente dos indivíduos" (SILVA, 2017). Além disso, a autora reforça a relação entre as pessoas da comunidade, as rezadeiras ou benzedeiras e a fé, salientando que as curas são eficazes pois há uma relação de solidariedade e afetividade entre o grupo em que além da fé da rezadeira em suas práticas, há a fé também das pessoas e um reconhecimento dessas práticas como eficazes.

Além disso, para a formação de rezadeiras ou benzedeiras deve haver um processo em que são passados os conhecimentos geralmente de mãe para filha, são atividades realizadas sem remuneração, mas são consideradas como um ofício (SILVA, 2017). Estudo feito por (MARIN e SCORSOLINI-COMIN, 2017) buscou compreender as experiências (pessoais, religiosas, sociais e culturais) de benzedeiras e sua influência para a promoção de saúde em comunidades em São Paulo e Minas Gerais, os autores apontam que "não somente no Brasil essas práticas populares de cura foram as primeiras formas de cuidado e atenção para com os adoentados". A rezadeira ou benzedeira teria um papel de intermediadora entre o homem e o sagrado. A partir disso, se alcança a cura, através da prece. De acordo com Queiroz e Puntel (1997) os saberes das benzedeiras consistem em uma cultura oral passada de geração a geração:

\footnotetext{
"A difusão do conhecimento que envolve a medicina caseira ocorre, via de regra, através de pessoas mais velhas na família, geralmente via sexo feminino, embora o sexo masculino não esteja excluído. O espiritismo kardecista e, mais modernamente, a umbanda são também importantes difusores de ervas medicinais e das formas terapêuticas que elas envolvem. Em princípio, o uso de ervas medicinais ocorre sem nenhum antagonismo com a lógica da medicina moderna oficial. Normalmente, este uso ocorre para os diversos mal-estares ou indisposições, os quais são avaliados como problemas menores que não merecem a preocupação ou o cuidado médico" (QUEIROZ, PUNTEL 1997).
}

Essa característica pode ser notada nos estudos que são realizados sobre as práticas das rezadeiras, em suma, sua maioria são passados de mãe para filha, no entanto, homens podem atuar também como curandeiros. Segundo Medeiros e colaboradores (2013), a relação entre o uso dessa terapia e o apelo ao misticismo 
é inerente a essa prática. Há relação significativa com o sobrenatural, em que o curandeiro é visto como elemento condutor para a realização deste.

De acordo com Nayara Lima Monteiro (2020) no sertão nordestino há também povos que realizam tais práticas:

\begin{abstract}
Marcado pelos registros históricos de povos originários, como os Kariri, o Cariri cearense está localizado na Chapada do Araripe inspirando a criatividade humana ritualizada através de manifestações culturais, celebrações, saberes, como os das erveiras, rezadeiras, parteiras tradicionais, realizados e cordelistas, poetas/tisas do sertão nordestino [...] Tais saberes e práticas estão presentes em diversas localidades, como nos Andes chilenos, no México, nas terras guaranis e dos povos amazônicos, no Cariri cearense, nos pampas gaúchos no Brasil, na Argentina e no Uruguai, territórios de Abya Yala, apresentando um núcleo semelhante que os interconecta nessa grande teia de territorialidades, saberes, ofícios, memórias, povos originários, tradicionais, identidades, gênero, espaço-tempo-dimensões.(MONTEIRO, 2020).
\end{abstract}

Isso reforça a origem em comum dos povos que originaram essas práticas. Sendo assim, esse conhecimento detido pelas rezadeiras as torna guardiãs da memória coletiva das classes populares, e também guardiãs da memória de luta e pelo bem-estar dos menos favorecidos. O aprendizado das rezas através da memorização das palavras mágicas, orações e receitas também podem ser entendidos como uma das principais estratégias da população empobrecida para resguardar bens simbólicos pertencentes a uma longa tradição. Isso pode ser ainda mais reforçado pela dificuldade de acesso a médicos e logo o trabalho de rezadeiras e curandeiras nessas comunidades para tratamento de sintomas leves, que não exigem a procura por um profissional da saúde, é fundamental em comunidades distantes de centros de atendimento médico ou de saúde, ou mesmo para pessoas em situação de vulnerabilidade social, que possuem dificuldades de acesso à saúde.

A relação de essas práticas estarem vinculadas a grupos sociais em vulnerabilidade ou marginalizadas no Brasil encontra-se no contexto histórico em que negros escravos foram postos à margem da sociedade mesmo após a baolição da escravatura. Segundo CONCEIÇÃO (2011), rezadeiras e rezadores se enquadram em um grupo social e cultural bem definido que diz respeito a trabalhadores rurais. Aplicam, portanto, os seus conhecimentos sobre ervas, plantas e emplastos associados à fé e crença em divindades sobrenaturais a fim de proporcionar cura de doenças. São pessoas normalmente consideradas sábias 
pelos mais jovens e são comumente procurados para realizar as práticas curativas ou compartilhar esse conhecimento. O conhecimento sobre ervas e práticas curativas detidas pelos anciãos das comunidades possui uma significativa importancia para essas pessoas. Logo, as comunidades que possuem origens em tribos africanas semelhantes podem deter conhecimentos semelhantes nos dias atuais por mais que estejam geograficamente separadas. Além disso, houve um grande intercâmbio de culturas de diferentes tribos nos quilombos o que propiciou a formação de culturas no Brasil com traços de duas ou mais crenças das tribos africanas, bem como resultou em algumas religiões, e assim, os conhecimentos das rezadeiras e benzedeiras a partir de suas práticas religiosas possuem efeito positivo no organismo humano, construindo também uma identidade latino-americana (MARALDI, MARTINS, 2017; MONTEIRO, 2020).

Segundo Aragão e Rodrigues (2020) nos rituais de reza há as orações mais variadas, e são voltadas normalmente para problemas cotidianos, em comunidades indígenas a missão de cura era voltada ao pajé (VIANNA, 2019). Além disso, vemos referência os antepassados de maneira frequente nos relatos das rezadeiras, conforme explicitado a seguir por Monteiro (2020):

\begin{abstract}
Dona Maria também na sua narrativa traz outro elemento que nos faz conectar a esse universo passado dos habitantes originários dessas terras antes ou do período de colonização, quando ela conta uma lenda sobre os índios terem "tapado uma barroquinha com ossos de 'sariema' ali no pé da serra que fez com que a água nascesse lá na nascente do Baixio do Boi", fazendo referência aos mitos e lendas dos Kariri bem conhecidos da nascente do rio Batateiras no Crato-CE (MONTEIRO, 2020).
\end{abstract}

Logo, tanto comunidades com origens indígenas quanto comunidades com origens africanas possuem suas peculiaridades. No entanto, o conhecimento etnocientífico desses povos está baseado na relação dos mesmos com a natureza. O uso de ervas, os cuidados com certos tipos de plantas, todos esses conhecimentos foram acumulados ao longo das gerações e passados para os representantes e detentores desse conhecimento. Segundo Werneck (2006) os saberes tradicionais ou empíricos podem ser considerados os conhecimentos obtidos a partir da experiência e são igualmente conhecimentos que os homens possuem e perpetuam por questões também de sobrevivência (WERNECK, 2006). 


\subsection{ETNOCIÊNCIAS NAS PRÁTICAS DE REZADEIRAS}

No Brasil, muitos estudos sobre as práticas de rezadeiras demonstram as experiências atuais de povos oriundos das matrizes africanas que ainda hoje resistem a sua cultura e suas práticas culturais no Rio de Janeiro. De acordo com a autora SOUZA (2018), encontrar uma rezadeira nos subúrbios cariocas têm sido cada vez mais difícil, e isso faz com que a autora demonstra preocupação. Da mesma forma, essas mulheres que praticam a reza e rituais de cura são estigmatizadas, e muitos acabam por definir como mera superstição, ignorando o fato dos conhecimentos étnicos e culturais presentes ali, bem como hábitos culturais pertencentes a uma origem.

O trabalho realizado por Almeida (2014) visa recuperar os saberes da cura pelas plantas a partir dos saberem tradicionais ou empíricos de moradores do município de Guarani das Missões no Rio Grande do Sul. O estudo observou mais estreitamente a relação entre as religiões e as plantas, e a medicina tradicional popular. Outro estudo realizado sobre as rezadeiras de Alagoas, SANTOS (2018), no qual foram descritos rituais e práticas, descrevem homens e mulheres como pessoas do meio rural que migraram para o meio urbano e assim realizam nas comunidades e prestam serviços de reza e cura para a comunidade. Ambos estudos reforçam a ideia do conhecimento obtido através de gerações. Em Mogi das Cruzes, São Paulo, a comunidade em questão estudada pelos autores Carvalho, Bonini, Almeida-Scabbia (2017) mostrou que ainda persiste o uso de plantas e que esse conhecimento foi passado de geração em geração. Dessa forma, no Brasil, é possível verificar que em todo o território há comunidades que perpetuam essas práticas iniciadas por antepassados.

Conforme visto anteriormente, o uso de ervas, compondo uma medicina popular, ainda é parte do cotidiano das rezadeiras, logo o uso de ervas é uma característica muito presente, e de acordo com Conceição (2014) uso da medicina preventiva:

Geralmente, no caso específico das Rezadeiras, elas desenvolviam uma medicina, tida, como preventiva na qual buscava expulsar a enfermidade do corpo antes mesmo que esta se instalasse. As Rezadeiras acreditavam ser possível se precaver de determinadas doenças por meio da utilização de "resguardos". A benzeção feita esporadicamente, bem como a abstinência em consumir determinadas misturas que envolvessem alguns alimentos, podem ser apontadas como indícios de prevenção dessas sábias 
mulheres. (CONCEIÇÃO, 2014).

Além disso, as rezas possuem variações, no entanto, no geral, elas possuem algumas características vinculadas à crença, ou ao sobrenatural. De acordo com Santos (2018) as palavras usadas são empregadas com valores simbólicos, seja para a cura de doenças ou para afastar maus espíritos. A descrição de alguns rituais pode ser dada mediante uma oração apenas para a cura de dois ou males diferentes.

\section{METODOLOGIA}

A abordagem metodológica escolhida para o desenvolvimento desse estudo foi à pesquisa bibliográfica, de cunho exploratório e descritivo, tendo uma abordagem qualitativa. Esse tipo de pesquisa permite identificar, organizar, relacionar, descrever, analisar fenômenos e comprovar uma hipótese ou compreender de melhor forma os fenômenos em questão. Dessa forma, a pesquisa qualitativa recobre atualmente um campo multidisciplinar, englobando as ciências humanas, naturais, sociais e matemáticas. Envolve estudos sobre a fenomenologia, hermenêutica, construtivismo e diversos outros métodos de investigação, que permitem ao pesquisador o aprofundamento no universo analisado (LAKATOS, MARCONI, 2003).

Para isso, o estudo foi desenvolvido a partir de algumas etapas próprias da pesquisa bibliográfica, e a partir da elaboração de um cronograma estabeleceu metas a ser atingidas, além de comprometimento com a análise dos dados. Dessa forma a pesquisa foi realizada a partir da delimitação do tema, estabeleceu-se os objetivos, e definiu-se a metodologia a ser adotada. Após, foi realizado o levantamento bibliográfico, de artigos e dissertações produzidos em Programas de Pós-graduação de universidades brasileiras, publicados em revistas e através de banco de dados, no período de 2006 até 2020 selecionado os materiais, realizado o fichamento e análise e interpretação dos dados e por fim a escrita. Isso permitiu a interpretação crítica das hipóteses, de modo imparcial, sem atribuir juízo de valor ao que outros autores apontam. Assim, a pesquisa realizada apresenta todos os

aspectos observados no assunto tratado bem como aponta lacunas e possibilidades de pesquisas futuras (LAKATOS, MARCONI, 2003) 
A pesquisa qualitativa se faz importante para o estudo de fenômenos sociais pois permite trabalhar com um universo de significados, motivos, aspirações, crenças, valores e atitudes, o que corresponde a um espaço mais profundo das relações, dos processos e dos fenômenos. Sendo assim, o presente estudo visa analisar qualitativamente os dados coletados visto que possibilita uma análise subjetiva sobre o fenômeno pesquisado através da compilação dos dados coletados (LAKATOS, MARCONI, 2003).

Trata-se de uma pesquisa de cunho exploratório, pois tem como objetivo proporcionar maior familiaridade com o problema, com vistas a torná-lo mais explícito. Além disso, visa o aprimoramento de ideias, buscando descobrir algumas intuições (GIL, 2002). Logo, o estudo foi realizado mediante uma pesquisa de artigos que tivessem como pauta as práticas das rezadeiras no Brasil em diferentes localidades do país, a fim de reunir os textos e dados e promover uma discussão sobre as diferentes identidades étnicas e as etnociências nas práticas das rezadeiras. Logo, foram consultadas, a partir de busca em ferramentas da internet com uso de palavras chave, bases de dados científicas e acadêmicas como a scielo, bvsalud, pepsic, entre outros de instituições acadêmicas.

\section{RESULTADOS E DISCUSSÃO}

O presente estudo permitiu analisar artigos e dissertações acerca das práticas das rezadeiras, considerando suas origens, a fim de compreender suas características e importância antropológica, cultural e social. Para isso, foram analisados os seguintes estudos: 
Tabela 1 - Estudos analisados e seus conceitos.

\begin{tabular}{|c|c|c|}
\hline AUTORES/TÍTULO & ANO & CONTEÚDO \\
\hline $\begin{array}{l}\text { ALMEIDA, Juliano. Bom Jardim dos Santos: } \\
\text { Trazendo as plantas de volta à vida. }\end{array}$ & 2014 & $\begin{array}{l}\text { Estudo etnográfico nas Missões no Rio Grande do Sul sobre o uso de plantas e sua } \\
\text { relação com a religião. Fala sobre medicina popular e os simbolismos para as } \\
\text { práticas religiosas. }\end{array}$ \\
\hline $\begin{array}{l}\text { BASTOS, Sandra Nazaré Dias. Etnociências } \mathrm{Na} \\
\text { Sala De Aula: Uma Possibilidade Para } \\
\text { Aprendizagem Significativa }\end{array}$ & 2013 & $\begin{array}{l}\text { Importância dos conhecimentos etnocientíficos que passaram a ser reconhecidos } \\
\text { como conhecimento legítimo e cooperativo para com as demais ciências. }\end{array}$ \\
\hline $\begin{array}{l}\text { CONCEIÇÃO, Alaíze dos Santos. "No meu } \\
\text { tempo, quando eu era criança, todo mundo } \\
\text { era rezador": trajetórias de vida e experiências } \\
\text { compartilhadas. Bahia. }\end{array}$ & 2011 & $\begin{array}{l}\text { Conhecimentos sobre ervas, plantas e emplastos associados a fé e crença em } \\
\text { divindades sobrenaturais a fim de proporcionar cura de doenças. Sobre as } \\
\text { rezadeiras, pessoas normalmente consideradas sábias pelos mais jovens e são } \\
\text { comumente procurados para realizar as práticas curativas ou compartilhar esse } \\
\text { conhecimento. }\end{array}$ \\
\hline $\begin{array}{l}\text { CARVALHO, Sergio Zanata; BONINI, Luci de } \\
\text { Mendes de Melo; ALMEIDA-SCABBIA, Renata } \\
\text { Jimenez de. Etnoconhecimento de plantas de } \\
\text { uso medicinal por benzedeiras/benzedores e } \\
\text { rezadeiras/rezadores de Anhembi e Mogi das } \\
\text { Cruzes SP }\end{array}$ & 2017 & $\begin{array}{l}\text { Sobre o uso de plantas medicinais por benzedeiras/ores e rezadeiras/ores de dois } \\
\text { municípios do estado de São Paulo, bem como se realiza uma reflexão sobre a } \\
\text { perseguição que eles/elas sofreram no passado e, no presente, seu papel como } \\
\text { agente de saúde. }\end{array}$ \\
\hline $\begin{array}{l}\text { DINIZ, Ericka Ellen Cardoso da Silva; DINIZ, } \\
\text { Emerson Cardoso da Silva. A Arte De Curar: } \\
\text { Saberes E Práticas De Rezadeiras E Benzedeiras } \\
\text { No Cuidar Da Saúde. }\end{array}$ & 2019 & $\begin{array}{l}\text { Sobre saberes e práticas das rezadeiras e benzedeiras e o seu papel na } \\
\text { sociedade, nas práticas ritualistas de cura na busca de gerar saúde e bem estar } \\
\text { ao indivíduo doente, destaca a importância dessas pessoas para os grupos sociais. }\end{array}$ \\
\hline $\begin{array}{l}\text { MACHADO, CJS., SANTIAGO, IMFL., and NUNES, } \\
\text { MLS., orgs. Gêneros e práticas culturais: desafios } \\
\text { históricos e saberes interdisciplinares. }\end{array}$ & 2010 & Livro acerca de gêneros e Práticas culturais \\
\hline $\begin{array}{l}\text { MARIN, Raquel Cornélio.; SCORSOLINI-COMIN, } \\
\text { Fabio. Desfazendo o "Mau-olhado": Magia, } \\
\text { Saúde e Desenvolvimento no Ofício das }\end{array}$ & 2017 & $\begin{array}{l}\text { Compreende as experiências (pessoais, religiosas, sociais e culturais) e as } \\
\text { transformações desenvolvimentais das benzedeiras ao longo de suas trajetórias de } \\
\text { vida, bem como sua relação com a promoção da saúde em suas comunidades }\end{array}$ \\
\hline
\end{tabular}




\begin{tabular}{|c|c|c|}
\hline Benzedeiras. & & através de entrevistas. \\
\hline $\begin{array}{l}\text { MONTEIRO, Nayara de Lima. Rezadeiras E } \\
\text { Erveiras Do Cariri: O Fio Decolonial Tecedor Das } \\
\text { Práticas De Cura Em Abya Yala. }\end{array}$ & 2020 & $\begin{array}{l}\text { Postula acerca do Cariri cearense, marcado pelos registros históricos de povos } \\
\text { originários, como os Kariri. }\end{array}$ \\
\hline $\begin{array}{l}\text { MENDES, Dulce Santoro. CAVAS, Cláudio São } \\
\text { Thiago. Benzedeiras e benzedeiros quilombolas } \\
\text { - construindo identidades culturais. }\end{array}$ & 2018 & $\begin{array}{l}\text { Propõe uma reflexão teórica acerca dos processos de construção das identidades } \\
\text { culturais de benzedeiras e benzedeiros moradores de comunidades quilombolas, } \\
\text { sob o enfoque dos estudos culturais e pós-coloniais. }\end{array}$ \\
\hline $\begin{array}{l}\text { OLIVEIRA, Érica Caldas Silva. Rezadeiras Da } \\
\text { Paraíba: Etnografia De Uma Crença Enraizada. }\end{array}$ & 2019 & $\begin{array}{l}\text { Análise de representações e significações de práticas de rezas e benzeduras por } \\
\text { mulheres paraibanas, relacionando-as a suas vivências de } \\
\text { rezadeira/benzedeira. }\end{array}$ \\
\hline Ribeiro, E. P., de Sena, M. L. M., \& Oreste, L. F. S. & 2018 & $\begin{array}{l}\text { DIÁLOGO COM O SAGRADO: Narrativas das benzedeiras e rezadeiras de Santo } \\
\text { Amaro }\end{array}$ \\
\hline $\begin{array}{l}\text { SANTOS, Sergiana Vieira dos. Para as ondas do } \\
\text { mar sagrado: uma etnografia dos rituais das } \\
\text { rezadeiras e rezadores de Delmiro Gouveia. }\end{array}$ & 2018 & $\begin{array}{l}\text { Sobre a prática, o ofício de cura realizada por rezadeiras do Rio de Janeiro, } \\
\text { especificamente do subúrbio carioca. A prática, o ofício de cura realizada por } \\
\text { rezadeiras do Rio de Janeiro, especificamente do subúrbio carioca. }\end{array}$ \\
\hline $\begin{array}{l}\text { SILVA, Leonice de Jesus. Etnicidade e cura } \\
\text { entre benzedeiras quilombolas de Rio de } \\
\text { Contas-ba }\end{array}$ & 2017 & $\begin{array}{l}\text { Identifica a constituição das identidades étnicas das benzedeiras das } \\
\text { comunidades quilombolas de Barra e Bananal; analisa a importância das } \\
\text { benzedeiras para a memória social e coletiva desses quilombos; e, por fim, } \\
\text { identifica os marcadores identitários nos rituais de benzimento. }\end{array}$ \\
\hline $\begin{array}{l}\text { SOUZA, Karina Fatima Gonçalves de. Ira, Emília } \\
\text { e Jurema: trajetórias e perspectivas de } \\
\text { rezadeiras no subúrbio carioca. }\end{array}$ & 2018 & $\begin{array}{l}\text { Aborda a prática, o ofício de cura realizada por rezadeiras do Rio de Janeiro, } \\
\text { especificamente do subúrbio carioca }\end{array}$ \\
\hline $\begin{array}{l}\text { VIANNA, Danielle Aparecida De Sousa As } \\
\text { Práticas De Cura Das Benzedeiras Na } \\
\text { Contemporaneidade: Sabedoria E Resistência. }\end{array}$ & 2019 & $\begin{array}{l}\text { Reflete sobre o papel e as práticas de cura das benzedeiras na } \\
\text { contemporaneidade, além das formas pelas quais poderiam ser inseridas nas } \\
\text { Políticas Públicas em Saúde. }\end{array}$ \\
\hline
\end{tabular}


Foi possível verificar que há semelhanças entre as práticas de rezadeiras em diferentes regiões do Brasil e suas diferenças estão relacionadas, provavelmente, às origens que esses povos possuem. As rezas são realizadas no sentido de promover a cura de doenças e a relação estabelecida entre os cidadãos e as rezadeiras está vinculada à fé, as crenças e a valorização dessa figura capaz de promover a cura ou a solução de problemas cotidianos, devido a sua sabedoria passada de geração a geração.

Os estudos analisados ainda permitem identificar o uso comum de plantas e ervas, também com o intuito de prevenir doenças. A atuação das benzedeiras é muito importante para essas comunidades principalmente devido às dificuldades de acesso aos médicos, não se restringindo seus serviços à reza, mas também à cura, a realização de partos, entre outros. Em alguns locais há dificuldade de encontrar essas pessoas devido à extinção dessas culturas que sofreram muitos preconceitos sendo caracterizadas apenas como superstição. Isso é preocupante, pois os conhecimentos empíricos acumulados ao longo de gerações são capazes de contribuir com a própria medicina. São originários de povos africanos e indígenas, além disso, as comunidades quilombolas existentes ainda preservam tais culturas de forma mais evidente.

\section{CONSIDERAÇÕES FINAIS}

O presente estudo possibilitou verificar a influência das identidades étnicas que influenciam as práticas das rezadeiras nos dias atuais, esses que vieram de matrizes africanas e indígenas. Assim, a partir da questão sobre quais as raízes dos conhecimentos etnocientíficos existentes para o desenvolvimento das práticas das rezadeiras, entende-se, portanto que são diferentes grupos, mas que, no Brasil, a partir do intercâmbio de culturas, puderam a partir de o contato estabelecer uma relação comum à maioria das comunidades a que pertencem as rezadeiras. Esse conhecimento vem da relação milenar do homem com a natureza, seu uso e manejo que permitiu a sua descoberta e aplicação para diversos males a partir dos conhecimentos empíricos, em outras palavras, experiências (a posteriori).

O presente trabalho realizado com o intuito de obter uma visão sistemática acerca da problemática verificou que, as crenças envolvidas no ofício das rezadeiras, bem como as religiões devem ser de fato reconhecidas como um 
mecanismo importante e de grande relevância que pode sim auxiliar positivamente $\mathrm{o}$ bom desenvolvimento das saúdes psicológica e social dos indivíduos, pois os estudos analisados permitiram perceber que essas rezadeiras são fundamentais para as comunidades em que se encontram.

\section{REFERÊNCIAS}

ARAGÃO e RODRIGUES. Vozes que curam e vozes que narram. Revista escritas do tempo, 2020.

ALMEIDA, Juliano. Bom Jardim dos Santos: Trazendo as plantas de volta à vida. Porto Alegre. 2014.

https://www.lume.ufrgs.br/bitstream/handle/10183/96151/000918230.pdf?sequence=1

BASTOS, Sandra Nazaré Dias. Etnociências Na Sala De Aula: Uma Possibilidade Para Aprendizagem Significativa. Curitiba, Paraná. 2013.

CONCEIÇÃO, Alaíze dos Santos. "No meu tempo, quando eu era criança, todo mundo era rezador": trajetórias de vida e experiências compartilhadas. Bahia. 2011.

CARVALHO, Sergio Zanata; BONINI, Luci de Mendes de Melo; ALMEIDA-SCABBIA, Renata Jimenez de. Etnoconhecimento de plantas de uso medicinal por benzedeiras/benzedores e rezadeiras/rezadores de Anhembi e Mogi das Cruzes - SP Revista Eletrônica Correlatio v. 16, n. 2 - dezembro de 2017.

DINIZ, Ericka Ellen Cardoso da Silva; DINIZ, Emerson Cardoso da Silva. A Arte De Curar: Saberes E Práticas De Rezadeiras E Benzedeiras No Cuidar Da Saúde. Universidade Federal da Paraíba -UFPB. 2019.

Etnociência reúne pesquisadores e comunidades tradicionais. Notícias Empresa Brasileira de Pesquisa Agropecuária (EMBRAPA) 2007. https://www.embrapa.br/busca-de-noticias//noticia/18019080/etnociencia-reune-pesquisadores-e-comunidades-tradicionais-

Intolerância religiosa contra rezadeiras Guarani Kaiowá. Le Monde Diplomatique Brasil. 23 de agosto de 2021. por Maiara Marinho. https://diplomatique.org.br/intolerancia-religiosacontra-rezadeiras-guarani-kaiowa/

LAKATOS, E. M.; MARCONI, M. A. Metodologia Científica. $3^{\circ}$ ed., São Paulo: Atlas, 2000.

MACHADO, CJS., SANTIAGO, IMFL., and NUNES, MLS., orgs. Gêneros e práticas culturais: desafios históricos e saberes interdisciplinares [online]. Campina Grande: EDUEPB, 2010. 256 p. https://static.scielo.org/scielobooks/tg384/pdf/machado-9788578791 193.pdf>

MARALDI, Everton de O. MARTINS, Leonardo B. Contribuições da Psicologia Evolucionista e das Neurociências para a compreensão das crenças e experiências religiosas. REVER -

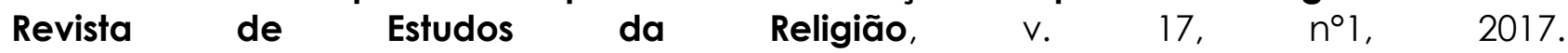
https://revistas.pucsp.br/index.php/rever/article/view/32704

MARIN, Raquel Cornélio.; SCORSOLINI-COMIN, Fabio. Desfazendo o "Mau-olhado": Magia, Saúde e Desenvolvimento no Ofício das Benzedeiras. Undoing the "Evil eye": Magic, Health and Development in the Craft of Folk Healers. Rev. Psicol. 2017. 
https://www.scielo.br/j/pcp/a/bKCy6WKB3fb3TbZwWPK7DZw/?̨lang=p†

MONTEIRO, Nayara de Lima. REZADEIRAS E ERVEIRAS DO CARIRI: O FIO DECOLONIAL TECEDOR DAS PRÁTICAS DE CURA EM ABYA YALA. 2020. https://nusserge.paginas.ufsc.br/files/2020/05/MONTEIRO-N.-L.-Rezadeiras.pdf

MENDES, Dulce Santoro. CAVAS, Cláudio São Thiago. Benzedeiras e benzedeiros quilombolas - construindo identidades culturais. Campo Grande, 2018. https://www.scielo.br/j/inter/a/DzBLLtsXYmTr5aZ3YGvTCGr/?lang=pt

OLIVEIRA, Érica Caldas Silva. Rezadeiras Da Paraíba: Etnografia De Uma Crença Enraizada. Informação em cultura, 2019.

POUTIGNAT, Phillipe; STREIFF-FENART, Jocelyne. Teorias da etnicidade. Seguido de grupos étnicos e suas fronteiras de Frederik Barth. Editora Unesp. 1998.

Ribeiro, E. P., de Sena, M. L. M., \& Oreste, L. F. S. (2018). DIÁLOGO COM O SAGRADO: Narrativas das benzedeiras e rezadeiras de Santo Amaro. ODEERE, 3(6), 366-374. https://doi.org/10.22481/odeere.v3i6.2724

QUEIROZ, MS., and PUNTEL, MA. A endemia hansênica: uma perspectiva multidisciplinar. Rio de Janeiro: Editora FIOCRUZ, 1997.

SILVA, Francisca Pimentel.; FRAXE, Therezinha Jesus. Saberes de populações tradicionais: etnociência em processos de bioconservação. Contribuciones a las Ciencias Sociales, España, ago. 2013.

https://www.eumed.net/rev/cccss/25/biodiversidade.html. Acesso em: 15 agosto. 2021.

SANTOS, Sergiana Vieira dos. Para as ondas do mar sagrado: uma etnografia dos rituais das rezadeiras e rezadores de Delmiro Gouveia. 2018.http://www.repositorio.ufal.br/bitstream/riufal/2548/1/Para\%20as\%20ondas\%20do\%20 mar\%20sagrado\%20\%20uma\%20etnografia\%20dos\%20rituais\%20de\%20rezadeiras\%20e\%20 rezadores\%20de\%20Delmiro\%20Gouveia.pdf

SILVA, Leonice de Jesus. Etnicidade e cura entre benzedeiras quilombolas de Rio de Contas-ba / Leonice de Jesus Silva. Jequié, 2017. http://www2.uesb.br/ppg/ppgrec/wpcontent/uploads/2018/07/DISSERTA\%C3\%87\%C3\%83 O-MESTRADO-LEONICE-DE-JESUS.pdf

STEFANELLO, A. G. F; NOGUEIRA, C. B. C. "Direitos Étnicos e Culturais na proteção dos Conhecimentos Tradicionais associados à biodiversidade brasileira". In: Nilton César da Silva Flores; Leonardo Macedo Poli; João Marcelo de Lima Assafim. (Org.). XXI Congresso Nacional do CONPEDI/UFF. led. Florianópolis: FUNJAB, 2012, v. 8, p. 236-259.

SOUZA, Karina Fatima Gonçalves de. Ira, Emília e Jurema : trajetórias e perspectivas de rezadeiras no subúrbio carioca 2018 . http://dippg.cefetrj.br/pprer/attachments/article/81/95 Karina\%20F\%C3\%A1tima\%20Gon\%C3\%A7alves\%20d e\%20Souza.pdf

VIANNA, Danielle Aparecida De Sousa As Práticas De Cura Das Benzedeiras Na Contemporaneidade: Sabedoria E Resistência. Goiânia, 2019. https://files.cercomp.ufg.br/weby/up/106/0/Danielle Aparecida De Sousa Vianna As pr\%C3\%Alticas de cura das benzedeiras na contemporaneidade sabedoria e r esist\%C3\%AAncia.pdf 
WERNECK, Vera Rudge. Sobre o processo de construção do conhecimento: o papel do ensino e da pesquisa. Ensaio: aval. pol. públ. Educ. 2006. 